\title{
ATIVIDADE NEUTRALIZANTE ANTI-HERPESVÍRUS BOVINO TIPOS 1 (BHV-1) E 5 (BHV-5) NO SORO DE BOVINOS IMUNIZADOS COM VACINAS CONTRA O BHV-1 ${ }^{1}$
}

\author{
NEUTRALIZING ACTIVITY TO BOVINE HERPESVIRUS TYPES 1 \\ (BHV-1) AND 5 (BHV-5) IN SERA OF CATTLE IMMUNIZED \\ WITH VACCINES AGAINST BHV-1
}

\author{
Fernanda Silveira Flores Vogel ${ }^{2}$ Eduardo Furtado Flores ${ }^{3}$ \\ Rudi Weiblen $^{4}$ Cíntia Farias Kunrath ${ }^{5}$
}

\begin{abstract}
RESUMO
Bezerros foram imunizados com duas vacinas contra o herpesvirus bovino tipo 1 ( $B H V-1$; vacina $A, n=28 ; B$, $n=28)$ ou com uma vacina contendo antígenos do BHV-1 e BHV$5(n=32)$ e a atividade neutralizante sérica antiBHV-1 e BHV-5 foi testada após três doses vacinais. Todos os animais $(n=88)$ produziram anticorpos com atividade neutralizante antiBHV-1 (titulos médios geométricos [GMT] de 13,1; 14,8 e 34,3 para as vacinas $A, B$ e $C$, respectivamente) e 82 animais $(93,2 \%)$ desenvolveram atividade neutralizante antiBHV-5 (GMTs: 10,6; 11,5 e 29,8, respectivamente). Nos três grupos vacinais, os títulos médios antiBHV-1 não diferiram dos títulos antiBHV-5. No entanto, comparando-se os titulos médios entre as vacinas, os titulos neutralizantes para o $B H V-1$ e $B H V-5$ foram superiores nos animais do grupo $C(p<0,01)$. Esse grupo também apresentou a maior proporção de reagentes ao BHV-5 (96,9\%, contra $85,7 \%$ da vacina $A$ e $92,9 \%$ da vacina B). Esses resultados demonstram que a vacina $C$ induziu titulos neutralizantes superiores contra os dois virus e que anticorpos induzidos por antígenos do BHV-1 (vacinas $A$ e $B$ ) possuem atividade neutralizante relevante também contra o $B H V-5$.
\end{abstract}

- NOTA -

Palavras-chave: herpesvirus bovino tipo 1, BHV-1, BHV-5, vacinas, neutralização cruzada.

SUMMARY

Calves were immunized with two vaccines against bovine herspevirus type 1 ( $B H V-1$; vaccine $A, n=28 ; B, n=28$ ) or with a vaccine containing $B H V-1$ and $B H V-5$ antigens (vaccine $C$, $n=32$ ) and the serum neutralizing activity against $B H V-1$ and BHV-5 was measured after three vaccine administrations. Neutralizing activity to BHV-1 was detected in sera of $100 \%$ $(n=88)$ of the animals (geometric mean titers [GMT] of 13.1; 14.8 and 34.3 for vaccines $A, B$ and $C$, respectively) whereas 82 sera (93.2\%) reacted to BHV-5 (GMTs: $10.6 ; 11.5$ and 29.8). In all three groups, the mean $\mathrm{BHV}-1$ titers did not differ from $\mathrm{BHV}-5$ titers. However, comparison among the vaccines demonstrated that the mean titers to $B H V-1$ and $B H V-5$ were higher in animals receiving vaccine $C(p<0.01)$. This vaccine also induced a higher proportion of reagents to $\mathrm{BHV}-5$ (96.9\%; against $85.7 \%$ for vaccine $A$ and $92.9 \%$ for vaccine $B$ ). These results demonstrate that vaccine $C$ induced higher neutralizing antibody titers against both viruses; and that antibodies induced by BHV-1 antigens

\footnotetext{
${ }^{1}$ Trabalho realizado com suporte financeiro do CNPq, MCT, CAPES e Finep (PRONEX em Virologia Veterinária, 215-96).

${ }^{2}$ Médico Veterinário, Aluno de Doutorado do Programa de Pós-graduação em Medicina Veterinária, Universidade Federal de Santa Maria (UFSM)

${ }^{3}$ Médico Veterinário, MSc., PhD., Professor Adjunto do Departamento de Medicina Veterinária Preventiva (DMVP), Centro de Ciências Rurais e do Departamento de Microbiologia e Parasitologia, UFSM. Bolsista do CNPq (520758/96-0). 97105-900, Santa Maria, RS. Fone/fax: 55-220-8034. E mail: flores@ccr.ufsm.br. Autor para correspondência

${ }^{4}$ Médico Veterinário, MSc., PhD., Professor Titular do DMVP, e do Departamento de Microbiologia e Parasitologia, UFSM. Bolsista do CNPq (520161/97-1)

${ }^{5}$ Estudante do Curso de Medicina Veterinária, UFSM.
} 
(vaccines $A$ and $B$ ) cross-reacted and displayed relevant neutralizing activity against BHV-5.

Key words: bovine herpesvirus type $1, B H V-1, B H V-5$, vaccine, cross-neutralization.

O herpesvírus bovino tipo 5 (BHV-5) é um alfaherpesvírus, previamente classificado como um subtipo do herpesvírus bovino tipo 1 (BHV-1). Surtos de meningo-encefalite pelo BHV-5 têm sido descritos com freqüência, principalmente no Brasil (WEIBLEN $\boldsymbol{e t}$ al., 1989; SALVADOR $\boldsymbol{e t}$ al., 1998) e Argentina (ODEON et al., 1998). Em contraste, a infecção respiratória e genital pelo BHV-1 possui distribuição mundial (KAHRS, 1977). O BHV-1 e BHV-5 são muito semelhantes antigenicamente entre si e apresentam uma extensa reatividade sorológica cruzada (BRATANICH et al., 1991; TEIXEIRA et al., 1998). A ampla distribuição da infecção pelo BHV-1, além do uso de vacinação em larga escala, tem sido utilizada para explicar a baixa ocorrência da infecção pelo BHV-5 na Europa e América do Norte (ELY et al., 1996; CASCIO et al., 1999). Reforçando essa hipótese, a infecção pelo BHV-5 tem sido descrita principalmente em países onde a prevalência do BHV-1 é relativamente baixa e que não utilizam vacinação em grande escala. No Brasil, vários estudos indicam a presença dos dois vírus na população bovina (WEIBLEN et al., 1989; ROEHE et al., 1998; TEIXEIRA et al., 1998).

Considerando a similaridade antigênica e a reatividade sorológica cruzada, este trabalho foi realizado para determinar a atividade neutralizante antiBHV-5, conferida por três vacinas contendo antígenos do BHV-1. Para isso, bovinos soronegativos foram divididos em três grupos e imunizados três vezes $(5 \mathrm{~m} \ell$, via intramuscular; dias 0,30 e 180) com vacinas que continham antígenos do BHV-1 (vacina A e B) ou com uma vacina contendo antígenos do BHV-1 e BHV-5 (vacina C). Um grupo $(\mathrm{n}=10)$ serviu de controle não-vacinado. O soro coletado no dia 210 foi testado pela técnica de soro-neutralização frente ao BHV-1 e BHV-5 (BRATANICH $\boldsymbol{e t} \boldsymbol{a l} .$, 1992).

Nos três grupos vacinais, os títulos médios geométricos (GMT) antiBHV-1 não diferiram dos títulos antiBHV-5. Em 53 animais $(60,2 \%)$, os títulos individuais (BHV-1 versus BHV5) não diferiram entre si (títulos iguais ou diferença de duas vezes). Alguns animais dos três grupos não apresentaram atividade neutralizante antiBHV-5 (grupo $\mathrm{A}=4 ; \mathrm{B}=2 ; \mathrm{C}=1$ )(Tabela 1). Esses animais possuíam títulos baixos $(\leq 16)$ contra o BHV-1. Os títulos neutralizantes médios antiBHV-1 e BHV-5 foram superiores $(\mathrm{p}<0,01)$ nos animais imunizados com a vacina $C$. A vacina $C$ também resultou no maior número de reagentes contra o BHV-5 (31 ou $96,9 \%$; contra 24 ou $85,7 \%$ da vacina A e 26 ou $92,9 \%$ da vacina B). Dentre os animais imunizados apenas com antígenos do BHV-1 (grupos A e B), seis $(10,7 \%)$ não apresentaram resposta sorológica antiBHV-5, contra apenas um animal (1/32 ou 3,1\%) do grupo C (BHV-1/BHV-5) que não soroconverteu ao BHV-5. A resposta sorológica de maior magnitude contra o BHV-1, e BHV-5, nos animais do grupo $\mathrm{C}$, pode ser atribuída, em grande parte, à utilização de adjuvante oleoso, enquanto a presença de antígenos do BHV-5 provavelmente foi a responsável pela maior proporção de animais reagentes a esse vírus nesse grupo.

Os resultados obtidos corroboram estudos anteriores que demonstraram a extensa reatividade sorológica entre o BHV-1 e BHV-5 (BRATANICH et al., 1991; TEIXEIRA et al., 1998). Além da reatividade sorológica in vitro, a possibilidade de proteção cruzada in vivo tem sido demonstrada com a vacinação e/ou infecção com o BHV-1 seguida de desafio com o BHV-5 (CASCIO et al., 1999; BELTRÃO et al., 2000). Embora os resultados do presente estudo não permitam inferências sobre proteção cruzada, eles demonstram que os títulos neutralizantes antiBHV-5 induzidos na maioria dos animais imunizados com o BHV-1 (vacinas A e B) foram comparáveis aos títulos tipo-específicos (antiBHV-1). No entanto, experimentos envolvendo vacinação e desafio são necessários para determinar se a resposta neutralizante antiBHV-5, desenvolvida por animais imunizados com o BHV-1, é suficiente para proteger os animais da doença neurológica, além de reduzir a replicação e a disseminação do vírus. Nas condições desse estudo, a inclusão de antígenos do BHV-5, na vacina $\mathrm{C}$, resultou no aumento do número de animais reagentes e com títulos superiores contra o BHV-5. Por isso, não obstante a similaridade antigênica e reatividade sorológica cruzada entre BHV1 e BHV-5, a inclusão de antígenos do BHV-5 em vacinas a serem utilizadas em regiões onde os dois vírus circulam, parece ser desejável para ampliar o grau e espectro da resposta imunológica contra esse vírus. 
Tabela 1 - Anticorpos neutralizantes anti-herpesvírus bovinos tipo 1 (BHV-1) e 5 (BHV-5) em bezerros imunizados com três vacinas contra o BHV-1.

\begin{tabular}{|c|c|c|c|c|c|c|c|c|c|c|}
\hline & \multicolumn{10}{|c|}{ Atividade neutralizante $^{\mathrm{a}}$} \\
\hline & \multicolumn{3}{|c|}{ AntiBHV-1 } & \multicolumn{3}{|c|}{ AntiBHV-5 } & \multicolumn{4}{|c|}{ Títulos SN antiBHV-1 x BHV-5 } \\
\hline & Positivos & $\mathrm{GMT}^{\mathrm{b}}$ & Variação & Positivos & GMT & Variação & Semelhantes $^{\mathrm{c}}$ & $\mathrm{BHV}-1>^{\mathrm{d}}$ & $\mathrm{BHV}-5>^{\mathrm{d}}$ & Total \\
\hline $\begin{array}{l}\text { A } \quad \text { BHV-1 } \\
\text { Vivo modificado }\end{array}$ & $28 / 28$ & 13,1 & $2-128$ & $24 / 28$ & 10,6 & $<2-64$ & 18 & 9 & 1 & 28 \\
\hline $\begin{array}{l}\text { B BHV-1 } \\
\text { Inativado } \\
\text { Adjuvante } \\
\mathrm{Al}(\mathrm{OH})_{3}\end{array}$ & $28 / 28$ & 14,8 & $2-128$ & $26 / 28$ & 11,5 & $<2-64$ & 20 & 8 & - & 28 \\
\hline $\begin{array}{l}\text { C BHV-1/ } \\
\text { BHV-5 } \\
\text { Inativados } \\
\text { Adjuvante oleoso }\end{array}$ & $32 / 32$ & 34,3 & $2->256$ & $31 / 32$ & 29,8 & $<2-128$ & 15 & 12 & 5 & 32 \\
\hline TOTAL & $88 / 88$ & 19,4 & $2->256$ & $82 / 88$ & 16 & $<2-128$ & 53 & 29 & 6 & 88 \\
\hline
\end{tabular}

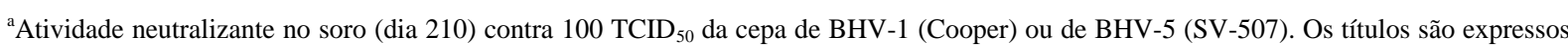
como a recíproca da maior diluição do soro capaz de impedir a replicação viral. Os 10 animais controles permaneceram soronegativos ao BHV-1 e BHV-5 durante o experimento (títulos neutralizantes $<2$ ).

b Título médio geométrico [GMT], considerando apenas as amostras positivas. As médias dos títulos foram transformadas em GMT pela relação: GMT $=2^{\mathrm{a}}$, onde " $a$ " é a média do título de anticorpos em cada vacina frente ao BHV-1 e BHV-5. A análise estatística foi feita baseada no teste de Saphiro-Wilk com nível de significância de $1 \%$.

${ }^{\mathrm{c}}$ Títulos iguais ou com diferença de uma diluição (2 x) (para o BHV-1 ou BHV-5).

${ }^{\mathrm{d}}$ Diferencas iguais ou superiores a 2 diluicões $(4 \mathrm{x})$.

\section{REFERÊNCIAS BIBLIOGRÁFICAS:}

BRATANICH, A.C., SARDI, S.I., SMITSAART, E.N., et al. Comparative studies of $\mathrm{BHV}-1$ variants by in vivo - in vitro tests. J Vet Med B, v.38, p. 41-48, 1991.

BELTRÃO, N., FLORES, E.F., WEIBLEN, R., et al. Infecção e enfermidade neurológica pelo herpesvírus bovino tipo 5 (BHV-5): coelhos como modelo experimental. Pesq Vet Bras, v.20, n.4, p.144-150, 2000.

CASCIO, K.E., BELKNAP E.B., SCHULTHEISS P.C., et al. Encephalitis induced by bovine herpesvirus 5 and protection by prior vaccination or infection with bovine herpesvirus 1 . J Vet Diagn Invest, v.11, p.134-139, 1999.

KAHRS, R.F. Infectious bovine rhinotracheitis: A review and update. J Am Vet Med Assoc, v.171, n.10, p.1055-1064, 1977.

ELY, R.W., d'OFFAY, J.M., RUEFER, A.H., et al. Bovine herpesviral encephalitis: a retrospective study on archived formalin-fixed, paraffin-embedded brain tissue. J Vet Diagn Invest, v.8, p.487-492, 1996
ODEON, A. Experiencias del grupo de sanidad animal del INTABalcarce referente a las infecciones causadas por el virus de la diarrea viral bovina (BVDV) y herpesvirus bovino (BHV). In: SIMPÓSIO INTERNACIONAL SOBRE HERPESVÍRUS BOVINO \& VÍRUS DA DIARRÉIA VIRAL BOVINA, 1998, Santa Maria, RS. Anais... Santa Maria : Pallotti, 1998. p.59.

ROEHE, P.M., TEIXEIRA, M.B., ESTEVES, P.A. et al Situação do BHV-1 e BHV-5 no Brasil. In: SIMPÓSIO INTERNACIONAL SOBRE HERPESVÍRUS BOVINO \& VÍRUS DA DIARRÉIA VIRAL BOVINA, 1998. Santa Maria, RS. Anais... Santa Maria : Pallotti, 1998. p.89.

SALVADOR S.C., LEMOS R.A.A., RIET-CORREA F., et al. Meningoencephalitis in cattle caused by bovine herpesvirus- 5 in Mato Grosso do Sul and São Paulo. Pesq Vet Bras, v.18, p.76-83, 1998.

TEIXEIRA, M.B., ESTEVES, P.A, COELHO, C.S.S., et al. Diferenças em níveis de anticorpos neutralizantes contra herpesvírus bovinos tipos 1 (BHV-1) e 5 (BHV-5). Pesq Agrop Gaúcha, v.4, n.1, p.61-65, 1998.

WEIBLEN, R., BARROS, C.S.L., CANABARRO, T.F., et al. Bovine meningoencephalitis from IBR virus. Vet Rec, v.124, p.66-67, 1989. 